Рарег

\title{
Absence of significant adverse events following thalidomide administration in bitches diagnosed with mammary gland carcinomas
}

\author{
C. B. de Campos, G. E. Lavalle, S Fialho Ligório, F. Camargo Nunes, R. A. Carneiro, \\ R. L. Amorim, G. D. Cassali
}

The aim of the study was to evaluate the incidence of adverse events (AEs) in female dogs diagnosed with advanced clinical stage mammary gland neoplasms following treatment with thalidomide. A prospective analysis of 29 female dogs treated with a high dose (HD) of $20 \mathrm{mg} / \mathrm{kg} /$ day of thalidomide for three months followed by a low dose (LD) of $10 \mathrm{mg} / \mathrm{kg}$ / day of thalidomide for three months was performed. All patients underwent physical examination, complete blood count, serum biochemistry profile, thoracic radiographs, and abdominal ultrasound analysis before the treatment and after the HD and LD. Clinical AEs were absent in 16/29 (55.17 per cent) patients following HD. An initial 3-5 day period of somnolence was described in 4/29 (13.79 per cent), prolonged somnolence in 5/29 (17.24 per cent), a short period of somnolence lasting only a few hours in $3 / 29$ (10.34 per cent), and difficulty to rouse was described in 5/29 (17.24 per cent) cases. Two patients (6.89 per cent) presented with prolonged somnolence that interfered with activities of daily living, resulting in anticipation of the dose reduction to the proposed LD after 15 days of the HD treatment. Following dose reduction, AE improvement was observed in all patients. Albeit remaining within the reference ranges, erythrocytes, haematocrit, total leucocyte count, neutrophils, lymphocytes, monocytes and $\gamma$-glutamyltranspeptidase showed significant alteration associated to thalidomide treatment.

\section{Introduction}

The images of devastating birth defects caused by thalidomide remains firmly embedded in the public consciousness (Stewart

\section{Veterinary Record (2016)}

C. B. de Campos, DVM MSc, Department of Veterinary Clinic and Surgery, School of Agricultural and Veterinary Sciences of the Sao Paulo State University (FCAV/UNESP) Jaboticabal Campus, Jaboticabal, Brazil

F. Camargo Nunes, DVM MSc PhD, G. D. Cassali, DVM MSc PhD, Laboratory of Comparative Pathology, Department of General Pathology, Federal University of Minas Gerais (UFMG), Belo Horizonte, Brazil

G. E. Lavalle, DVM MSc PhD,

R. A. Carneiro, DVM MSc PhD, Department of Veterinary Clinic and Surgery, Veterinary School, Federal University of Minas Gerais (UFMG), Belo Horizonte, Brazil

S Fialho Ligório, BSc MSc PhD, Department of Pharmaceutical and doi: 10.1136/vr.103764

Biotechnological Development, Fundação Ezequiel Dias, Belo Horizonte, Brazil

R. L. Amorim, DVM MSc PhD, Department of Veterinary Clinics, College of Veterinary Medicine and Animal Science, Sao Paulo State University (FMVZUNESP) - Botucatu Campus, Botucatu, Brazil

C. B. de Campos is also at Laboratory of Comparative Pathology, Department of General Pathology, Federal University of Minas Gerais (UFMG), Belo Horizonte, Brazil

E-mail for correspondence: cassalig@icb.ufmg.br

Provenance: Not commissioned; externally peer reviewed

Accepted August 2, 2016
2014). Thalidomide was synthesised in Germany in 1954 and marketed in various parts of the world as a sedative and a hypnotic, considered most effective as an anti-emetic in early pregnancy (McBride 1977). The first toxic effect of thalidomide was recorded by Florence (1960), who reported the early signs of peripheral neuropathy (PN), followed by reports on malformations of the extremities (McBride 1961). Thalidomide was associated with congenital deformities and the drug was withdrawn from the market (McBride 1977, Lenz 1988).

Angiogenesis inhibition, immunomodulation and cytokine modulation have been considered, but the exact mechanism of action of thalidomide for neoplastic diseases remains unknown (Singhal and Mehta 2002). Anti-angiogenic properties were described as a possible consequence of thalidomide therapy, but not the mechanism of action that explained its clinical effect (Stewart 2014). Chamberlain and others (2014) and Ito and others (2010) demonstrated the importance of thalidomide and related immunomodulatory drugs (IMiD) immunomodulatory agents binding to the Cul4-Rbx1-DDB1-Cereblon E3 ubiquitin ligase complex, leading to the therapeutic and teratogenic effects of these drugs. Thalidomide has shown activity in the treatment of erythema nodosum leprosum, oral ulcers in Behçet disease, wasting syndrome in patients with acquired human immunodeficiency disease, and is under investigation for rheumatoid arthritis, inflammatory bowel diseases and other autoimmune disorders (Dimopoulos and Eleutherakis-Papaiakovou 2004). Thalidomide has also been studied in several types of human neoplastic diseases, such as multiple myeloma, Kaposi's sarcoma, breast cancer, gliomas, colon cancer, prostate cancer, renal cell 
carcinoma and others (Singhal and Mehta 2002, Dimopoulos and Eleutherakis-Papaiakovou 2004). Although Teo and others (2001) evaluated the safety profile of thalidomide in healthy dogs, few studies have attempted to evaluate the efficacy of thalidomide in canine clinical trials.

Mammary gland tumours are the most common neoplasms in intact female dogs (Brodey and others 1983). Surgery is the mainstay of treatment for canine mammary gland tumours and is the single most effective modality for local tumour control. More advanced tumours may require adjuvant therapy (Novosad 2003, Sorenmo 2003), and chemotherapy is often recommended for dogs with mammary tumours considered to be at risk for metastasis or recurrence (Sorenmo and others 2013). However, there is no standard recommendation for the use of chemotherapy (Cassali and others 2014). High-quality trials are needed to evaluate the efficacy of chemotherapy protocols as well as to provide guidance for treating high-risk mammary gland tumours (Sorenmo 2003, Sorenmo and others 2013). Previous studies evaluating thalidomide in the 4T1 mice mammary tumour model have demonstrated a clear benefit in controlling primary tumour development, as well as metastatic progression (De Souza and others 2012, De Souza and others 2014, Dos Reis and others 2014). Two pilot studies involving thalidomide were performed in veterinary medicine: thalidomide induced prolonged responses as a single drug in canine haemangiosarcomas (Woods and others 2004), and a multimodal approach including bleomycin, piroxican, thalidomide, radiotherapy and surgery was considered to have encouraging results in feline unresectable head and neck squamous cell carcinomas (Marconato and others 2013).

An adverse event (AE) is defined as any unfavourable and unintended sign, clinical sign or disease temporally associated with the use of a medical treatment that may or may not be considered related to the medical treatment (Veterinary Co-operative Oncology Group 2004). The aim of the present study was to evaluate $\mathrm{AE}$ in female dogs diagnosed with advanced clinical stage mammary gland neoplasms following two different doses of thalidomide.

\section{Materials and methods}

A prospective analysis of female dogs admitted to the Veterinary Hospital of the Federal University of Minas Gerais (UFMG), Brazil, diagnosed with mammary gland neoplasms was performed. The neoplasms were diagnosed at the Laboratory of Comparative Pathology of the Institute of Biological Sciences, UFMG, Brazil.

Clinical staging according to the TNM (tumour, node, metastases) system established by WHO for canine mammary tumours was performed. This system evaluates: tumour size $\left(\mathrm{T}_{1}: 0-3 \mathrm{~cm}\right.$; $\mathrm{T}_{2}: 3-5 \mathrm{~cm} ; \mathrm{T}_{3}:>5 \mathrm{~cm}$ ); neoplastic involvement of regional lymph nodes $\left(\mathrm{N}_{0}\right.$ : non-metastatic; $\mathrm{N}_{1}$ : metastatic); and presence of distant metastasis ( $M_{0}$ : non-metastatic; $M_{1}$ : metastatic). Afterwards, cases were divided into five stages: I $\left(\mathrm{T}_{1} \mathrm{~N}_{0} \mathrm{M}_{0}\right)$, II $\left(\mathrm{T}_{2} \mathrm{~N}_{0} \mathrm{M}_{0}\right)$, III $\left(\mathrm{T}_{3} \mathrm{~N}_{0} \mathrm{M}_{0}\right)$, IV $\left(\mathrm{T}_{1-3} \mathrm{~N}_{1} \mathrm{M}_{0}\right)$ and $\mathrm{V}\left(\mathrm{T}_{1-3} \mathrm{~N}_{0-1} \mathrm{M}_{1}\right)$ (Owen 1980, Sorenmo and others 2013). Patients presenting with advanced clinical staging (stages IV and V) were included in the study.

Thalidomide was administered in single daily oral doses for six months. In order to avoid possible undesirable effects of the drug due to its sedative properties, pet owners were instructed to administer the medication at night. During the first three months, patients were subjected to a high dose (HD) $(20 \mathrm{mg} / \mathrm{kg})$ of thalidomide, followed by a low dose (LD) $(10 \mathrm{mg} / \mathrm{kg}$ ) for three months. The doses used in the present study were based on two previous canine studies that used daily doses of 100 $400 \mathrm{mg}$ to dogs diagnosed with haemangiosarcomas (Woods and others 2004) and proposed 3.3-6.5 mg/kg, 6.6-13 mg/kg, $13.3-$ $26 \mathrm{mg} / \mathrm{kg}$ to dogs with varied malignant neoplasms (Jankowski and others 1999). Neither study found any important AE. Treatment with thalidomide was initiated following a minimum period of two weeks after the previous treatment (mainly chemotherapy) in order to allow patient recovery. Informed client consent was obtained in all cases.

Thalidomide tablets were manufactured at the Ezequiel Dias Foundation (EDF), Brazil, which meets the Brazilian Health Surveillance Agency's good manufacturing practices for this production. The EDF is the only producer of thalidomide in Brazil.

Pet owners were instructed to administer the medication using disposable gloves. Individual prescriptions were given for a 28-day period and pet owners signed an informed-consent form acknowledging that the intact bitches were not allowed to reproduce, that the administration of thalidomide was exclusively for the dog enrolled in the study and that any unused medication should be returned for adequate disposal at the EDF. Thalidomide was given to pet owners in tablets weighting $370 \mathrm{mg}$ (100 mg of thalidomide + excipients). Doses were rounded to the nearest whole tablet size since reformulation was not possible. Therefore, the $\mathrm{HD}$ and $\mathrm{LD}$ range was approximately $18-22 \mathrm{mg} / \mathrm{kg}$ and $8-12 \mathrm{mg} / \mathrm{kg}$, respectively. The effect of food intake on thalidomide absorption in human beings is considered minimal (Teo and others 2004). Pet owners were instructed to be careful while collecting and disposing of faeces, urine and other bodily fluids of the animals.

All patients underwent complete history evaluation, physical examination, serum exams consisting of a complete blood count $(\mathrm{CBC})$, serum biochemistry profile (SBP) and thoracic radiographs, and abdominal ultrasound at the baseline. Patients were clinically evaluated monthly and serum and imaging exams were repeated every three months. Additional exams or more frequent serum and imaging exams were requested when necessary, for example, respiratory clinical signs leading to additional thoracic radiographs. Pet owners were interviewed every month to assess any clinical observations of the patients that could be associated to the thalidomide treatment.

Clinical history, physical examination, serum and imaging exams performed during the $\mathrm{HD}$ and $\mathrm{LD}$ thalidomide treatment were compared with the baseline evaluation. In addition, VCOG-CTCAE (Veterinary cooperative oncology group common terminology criteria for adverse events) criteria were applied to describe AEs. AEs were classified as: mild (grade 1), moderate (grade 2), severe (grade 3), life-threatening (grade 4) and death related to the $\mathrm{AE}$ (grade 5) (Veterinary Co-operative Oncology Group 2004).

Descriptive statistics are presented for AE findings. Statistical analyses of CBC and SBP were performed with Student's $t$ test, analysis of variance, Wilcoxon signed-rank test, Friedman test and Kruskal-Wallis test, depending on normality, the number of observations and whether the observations were paired. Results were considered statistically significant when $\mathrm{P} \leq 0.05$

All procedures were performed under the appropriate guidelines and with the approval of the Ethics Committee for Animal Experimentation of the UFMG (protocol number 132/2011) and the Ethics Committee for Animal Experimentation of the São Paulo State University (Jaboticabal Campus) (protocol number 021846/14)

\section{Results}

Twenty-nine patients were studied. Mean age was 12.6 \pm 2.1 years. Six patients (20.69 per cent) presented with distant metastases, classified as clinical stage V. All patients were submitted to surgical excision of the primary neoplasm and adjuvant chemotherapy was performed in 28/29 (95.55 per cent) cases. Chemotherapy consisted of carboplatin, one dose every 21 days for a total of four doses given intravenously at $300 \mathrm{mg} /$ $\mathrm{m}^{2}$. Seven patients were not subjected to the LD treatment: $6 / 29$ (20.69 per cent) patients due to death during the first three months of the HD treatment, and 1/29 (3.45 per cent) due to treatment abandonment by the pet owner.

No significant alterations were found when evaluating the thoracic radiographs following $\mathrm{HD}$ and $\mathrm{LD}$ of thalidomide. Abdominal ultrasounds demonstrated spleen enlargement in 4/ 
TABLE 1: Complete blood count (CBC) and serum biochemistry profile (SBP) results before thalidomide treatment (BT), following three months of the high dose (HD) $(20 \mathrm{mg} / \mathrm{kg} /$ day) treatment and following three months of the low dose (LD) (10 mg/kg/ day) treatment of female dogs with advanced stage mammary neoplasms receiving thalidomide therapy

\begin{tabular}{|c|c|c|c|c|}
\hline $\mathrm{CBC} / \mathrm{SBP}$ & $\mathrm{BT}+\mathrm{HD} \dagger$ & $P$ value & $B T+H D+L D \neq$ & $P$ value \\
\hline \multirow[t]{3}{*}{ Erythrocytes§ $\left(10^{6} / \mathrm{mm}^{3}\right)$} & BT $5.6 \pm 0.9$ & 0.2903 & ВT $5.5 \pm 1$ & $0.0201^{*}$ \\
\hline & HD $5.8 \pm 1.1$ & & HD $6.1 \pm 1$ & \\
\hline & & & LD $6.4 \pm 1.2$ & \\
\hline \multirow[t]{3}{*}{ Haemoglobin§ (\%) } & BT $13.1 \pm 2.3$ & 0.6184 & BT $13.3 \pm 2.5$ & 0.1010 \\
\hline & HD $13.3 \pm 2.4$ & & HD $14.1 \pm 1.8$ & \\
\hline & & & LD $14.7 \pm 2.4$ & \\
\hline \multirow[t]{3}{*}{ Haematocritฤ (\%) } & BT 41 (24-51) & 0.2124 & BT $40.5(26-44)$ & $0.0121^{*}$ \\
\hline & HD $41(27-50)$ & & HD 43.5 (34-48) & \\
\hline & & & LD $43(29-50)$ & \\
\hline \multirow[t]{3}{*}{ MCVף (fl) } & ВT 70.9 (61.4-80.7) & 0.8124 & BT 70 (61.4-76.1) & 0.2359 \\
\hline & HD $70.2(61-95.7)$ & & HD $70.2(61-77.6)$ & \\
\hline & & & LD 64.8 (58.5-79) & \\
\hline \multirow[t]{3}{*}{ MCH§ (pg) } & BТ $23.5 \pm 1.9$ & 0.6818 & BT $23.9 \pm 2.5$ & 0.3910 \\
\hline & HD $23.3 \pm 2.5$ & & HD $23.2 \pm 1.8$ & \\
\hline & & & LD $22.7 \pm 1.7$ & \\
\hline \multirow[t]{3}{*}{ MCHC§ (\%) } & ВТ $32.9 \pm 3.8$ & 0.8392 & BT $34.1 \pm 4.4$ & 0.4595 \\
\hline & HD $32.8 \pm 2.6$ & & HD $33.4 \pm 1.2$ & \\
\hline & & & LD $34.7 \pm 1.4$ & \\
\hline \multirow[t]{3}{*}{ RDWๆ (\%) } & BT $14.1(0-19.3)$ & 0.6944 & BT $14.4(13.4-19.3)$ & 0.3519 \\
\hline & HD $14.2(0-19.5)$ & & HD 14.8 (12.1-19.5) & \\
\hline & & & LD $13.1(0-16.2)$ & \\
\hline \multirow{3}{*}{ Total leucocyte count $\left(/ \mathrm{mm}^{3}\right)$} & ВТ 8540 (1970-22300) & $0.0073^{*}$ & BT 8540 (2010-13500) & 0.1870 \\
\hline & HD 10900 (5850-44000) & & HD 9150 (5850-23200) & \\
\hline & & & LD 10435 (8260-30200) & \\
\hline \multirow[t]{3}{*}{ Segmented neutrophils $\left(/ \mathrm{mm}^{3}\right)$} & BT 6448 (281.4-20516) & $0.0064 *$ & BT 6536 (281.4-11745) & 0.3046 \\
\hline & HD 8719 (4471-41360) & & HD 7247 (4856-21576) & \\
\hline & & & LD 9877 (4862-27180) & \\
\hline \multirow[t]{3}{*}{ Lymphocytes $\Uparrow\left(/ \mathrm{mm}^{3}\right)$} & BT 1364 (476-2291) & $0.0451^{*}$ & BT 1467 (956.2-1806) & 0.0854 \\
\hline & HD $751.4(240-4128)$ & & HD 758.7 (351-1926) & \\
\hline & & & LD 1416 (712-1830) & \\
\hline \multirow[t]{3}{*}{ Eosinophilsף $\left(/ \mathrm{mm}^{3}\right)$} & BT $272(0-3060)$ & 0.9999 & BT $258(0-956.2)$ & 0.9563 \\
\hline & HD 332.5 (0-2091) & & HD 321 (105-520.1) & \\
\hline & & & LD $302(0-1791)$ & \\
\hline \multirow[t]{3}{*}{ Monocytes $\left(/ \mathrm{mm}^{3}\right)$} & BT 165.8 (0-2314) & $0.0064 *$ & BT $40.2(0-751.3)$ & $0.0272^{*}$ \\
\hline & HD 494 (0-2976) & & HD 420 (148.6-929) & \\
\hline & & & LD 472 (341.2-1661) & \\
\hline Platelet count $\emptyset\left(/ \mathrm{mm}^{3}\right)$ & BT $180500(27000-715000)$ & 0.3683 & BT $265500(106000-715000)$ & 0.9674 \\
\hline & HD $277500(64400-834000)$ & & HD $267000(99000-399000)$ & \\
\hline & & & LD $208000(160000-532000)$ & \\
\hline BUNף (mg/dL) & BT $41.2(20.8-100.8)$ & 0.1688 & BT $28.93(20.8-57)$ & 0.6197 \\
\hline & HD $49.9(15.4-165.5)$ & & HD 43.18 (28.9-61.1) & \\
\hline & & & LD $42.5(20.3-69)$ & \\
\hline Creatineף (mg/dL) & BT 1 (0.6-2.6) & 0.9880 & BT $1.1(0.6-1.6)$ & 0.9563 \\
\hline & HD $1(0.2-4.9)$ & & HD $0.9(0.6-1.6)$ & \\
\hline & & & LD $1.5(0.5-1.8)$ & \\
\hline AST $(\mathrm{U} / \mathrm{L})$ & BT $54.4(0-117.8)$ & 0.1726 & BT $50.7(0-117.8)$ & 0.9537 \\
\hline & HD $60.2(29-216.9)$ & & HD $64.5(40.2-77)$ & \\
\hline & & & LD $37.3(33.8-103.2)$ & \\
\hline $\operatorname{ALT}\rceil(U / L)$ & BT 81.5 (34.2-423.2) & 0.7609 & BT 138.5 (60.2-313) & 0.5705 \\
\hline & HD 93.9 (31.5-271) & & HD 95.3 (75.8-271) & \\
\hline & & & LD 67.9 (38-136.1) & \\
\hline GGT $(\mathrm{U} / \mathrm{L})$ & BT $1.8(0-17)$ & 0.3101 & BT $4.5(0-17)$ & $0.0206^{*}$ \\
\hline & HD $2.3(0-38.5)$ & & HD $8.9(0-38.5)$ & \\
\hline & & & LD $0.6(0-1.2)$ & \\
\hline Alkaline phosphatase & BT 59 (6-889.2) & 0.2334 & BT $75.4(10-348)$ & 0.6914 \\
\hline & HD $82(13.5-500)$ & & HD $108.8(15-500)$ & \\
\hline & & & LD $61.4(25-266.5)$ & \\
\hline Amylase (U/L) & ВТ 650 (484-2115) & 0.9453 & BT 694 (627-761) & 0.5000 \\
\hline & HD 818.5 (5.8-1230) & & HD 784.6 (547-1022) & \\
\hline & & & LD 905.2 (671-1139) & \\
\hline Total proteinๆ (g/dL) & BT $6.6(5.5-12.8)$ & 0.9460 & BT 6.1 (5.5-12.8) & 0.7682 \\
\hline & HD $6.7(5.6-9.2)$ & & HD $7.4(5.6-9.2)$ & \\
\hline & & & LD $6.6(6.1-7.9)$ & \\
\hline Albumin $(\mathrm{g} / \mathrm{dL}) \S$ & ВT $2.8 \pm 0.3$ & 0.6642 & BT $3 \pm 0.5$ & 0.4940 \\
\hline & HD $2.7 \pm 0.5$ & & HD $3.1 \pm 0.1$ & \\
\hline & & & LD $2.8 \pm 0.5$ & \\
\hline Globulinף (g/dL) & BT 4 (2.6-9.3) & 0.7493 & BT 3.8 (2.9-9.3) & 0.6528 \\
\hline & HD $4.1(2.7-6.1)$ & & HD 4.625 (3-6.1) & \\
\hline & & & LD 4 (2.9-5.8) & \\
\hline
\end{tabular}

\footnotetext{
"Statistically significant values.
}

Differences in BT and HD values in† and ‡are due to different sample sizes (seven more animals in†)

$\S$ Parametrical values expressed as mean \pm sd

ПNon-parametrical values expressed as median (range)

ALT, alanine aminotransferase; AST, aspartate aminotransferase; BUN, blood urea nitrogen; GGT, $\gamma$-glutamyltranspeptidase; MCH, mean corpuscular haemoglobin; MCHC, mean corpuscular haemoglobin concentration; MCV, mean corpuscular volume; RDW, red cell distribution width

18 (22.22 per cent) cases, increased renal cortical echogenicity in $3 / 18$ (16.66 per cent) cases and diffuse hepatomegaly in $2 / 18$ (11.11 per cent) cases.
Pet owner interviews demonstrated some $\mathrm{AE}$ related to the thalidomide treatment. HD was not associated with AE in $16 / 29$ (55.17 per cent) patients. An initial three-day to five-day period 
of somnolence was described in 4/29 (13.79 per cent) cases, a short somnolence period lasting only a few hours following thalidomide administration in $3 / 29$ (10.34 per cent), while prolonged somnolence during the entire HD treatment period was found in $5 / 29$ (17.24 per cent), and 5/29 (17.24 per cent) animals were found to be difficult to rouse in the morning. The somnolence AEs described were considered grade 2. In addition, loss of appetite with no significant association to weight loss (grade 1) was found in 3/29 (10.34 per cent). One (3.44 per cent) animal presented with transient mild ataxia (grade 2 ) during the first days of thalidomide administration and clinical signs disappeared without additional treatment or thalidomide interruption. Following dose reduction, all patients that reported AEs presented with a significant improvement of all clinical findings. Two patients (6.89 per cent) presented with prolonged somnolence that was found to interfere with activities of daily living, resulting in anticipation of the dose reduction to the proposed $\mathrm{LD}$ after 15 days of the HD treatment. Following dose reduction, AE improvement was observed in all patients. However, 1/29 (3.44 per cent) animals still presented with a short period somnolence lasting only a few hours following thalidomide administration and $1 / 29$ (3.44 per cent) animals was found to be difficult to rouse in the morning.

Patients did not present with significant bodyweight alteration and gastrointestinal, cardiac, dermatological, endocrine, respiratory, genitourinary or neurological signs associated to the studied treatment. No definitive signs of PN were observed.

$\mathrm{CBC}$ and SBP results at the baseline, following three months of the $\mathrm{HD}$, and three months of the LD thalidomide administration are presented in Table 1. Basophils and band neutrophils were only found in four and six CBCs, respectively, not allowing statistical analysis. Baseline evaluations were performed after chemotherapy in the majority of patients, which explains the relatively low $\mathrm{CBC}$ values.

Mean and median values of the $\mathrm{CBC}$ and SBP components were also compared with reference laboratory values for each component. CBC evaluation demonstrated a statistically significant increase in erythrocytes, haematocrit, total leucocyte count, segmented neutrophils and monocytes, and a statistically significant decrease in lymphocytes after the thalidomide treatment. However, erythrocyte, haematocrit, total leucocyte count, segmented neutrophil, and monocyte median and mean values remained within reference ranges. Lymphocyte median values were slightly lower than the $1000 / \mathrm{mm}^{3}$ minimum reference value. Thalidomide administration did not statistically influence haemoglobin, mean corpuscular volume, mean corpuscular haemoglobin, mean corpuscular haemoglobin concentration, red cell distribution width, eosinophil, and platelet median and mean values.

SBP evaluation demonstrated HD thalidomide associated with a statistically significant decrease in $\gamma$-glutamyltranspeptidase (GGT) values following the LD thalidomide treatment. However, GGT values remained within reference ranges. Thalidomide administration did not statistically influence blood urea nitrogen, creatine, aspartate aminotransferase (AST), alanine aminotransferase, alkaline phosphatase, amylase, total protein, albumin, and globulin median and mean values.

CBC and SBP evaluation through VCOG-CTCAE criteria demonstrated an absence of grade $5 \mathrm{AE}$ and only one grade $4 \mathrm{AE}$. The grade 4 finding referred to serum creatine levels of a patient presenting with bilateral renal metastasis, and therefore was not considered an AE related to therapy. No statistically significant difference was found when evaluating the frequencies of grade 1 , grade 2 and grade 3 findings at the baseline and after three months of the HD and LD of thalidomide.

\section{Discussion}

Standard treatment for dogs with mammary gland tumours consists of surgery and there are no established guidelines for adjunctive therapy. However, systemic therapy is routinely recommended in high-risk cases characterised by regional lymph node metastasis, large tumours and aggressive histology (lymphatic and vascular invasion or high histological grade) (Sorenmo 2003, Sorenmo and others 2013). Lavalle and others (2012) described a benefit in canine malignant mammary gland neoplasms with advanced clinical staging from complementary therapy with chemotherapy with or without Cox-2 inhibitors. Clinical benefit of adjuvant chemotherapy in disease-free interval and overall survival was also described by Karayannopoulou and others (2001). More studies involving different effective adjuvant therapeutic protocols are warranted.

Woods and others (2004) suggested that, while the optimal dose and schedule of thalidomide administration in dogs remains to be determined, the absence of myelosuppressive and other important AEs enables thalidomide to be used in combination with chemotherapy, possibly representing a novel treatment approach that targets tumours and their microenvironment.

Severe teratogenicity, drowsiness, constipation, nausea, weakness, fatigue, lethargy, tingling and/or numbness in the hands and the feet, dizziness, thromboembolism, headache and skin rash are predominant $\mathrm{AEs}$ of thalidomide in human beings. Sedation is a major AE. Furthermore, $\mathrm{PN}$ has been described in 30-70 per cent of patients (Escudier and others 2002, Singhal and Mehta 2002, Dimopoulos and Eleutherakis-Papaiakovou 2004). PN is defined as any form of damage, inflammation or degeneration of peripheral nerves, and is typically symmetrical and characterised by painful paraesthesia of the hands and feet, often accompanied by sensory loss in the feet. Dose and treatment duration of thalidomide are the two most crucial risk factors for development of PN (Delforge and others 2010). Teo and others (2001) suggest a difference in thalidomide toxicity among species. In contrast to human beings, Teo and others (2000) did not describe thalidomide-induced PN in beagles. The lack of PN in dogs might be due to the absence of a particular neurotoxic product, possibly resulting from the production of different metabolites or hydrolysis products by dogs and human beings that may be involved in thalidomide-induced PN.

In addition, the incidence of canine PN may be underestimated due to limitations in the perception of clinical signs by human beings and insufficient thorough routine neurological examination and exclusion of $\mathrm{PN}$ is not possible without more invasive tests. In the present study, the short thalidomide treatment length may also be associated to lower risk of PN. Nonetheless, PN should not be considered a limiting factor for canine thalidomide treatment (Teo and others 2000).

In human beings, if the AEs are tolerable, patients should be encouraged to continue the drug at the same dose. Occasionally, the drug may need to be discontinued for a period of two to three weeks and then started again at a lower dose. Most studies have utilised thalidomide in a single bedtime dose. Patients with excessive drowsiness in the morning may occasionally divide the dose. Since the half-life of the drug in human beings is six to seven hours, this may be a better way to administer the drug (Singhal and Mehta 2002). In general, management of AE is based on four principles: dose adjustment or temporary interruption; avoidance of agents that enhance thalidomide-induced $\mathrm{AE}$; administration of agents or measures that prevent or relieve side effects; and clinical and laboratory monitoring for detection or prevention of toxicity (Dimopoulos and EleutherakisPapaiakovou 2004). The effort in altering the dosing strategy in order to maintain dose intensity is expected to be beneficial in tumour control.

Teo and others (2001) evaluated the safety profile of thalidomide in beagles in higher dosages $(43-1000 \mathrm{mg} / \mathrm{kg}$ ) than the present study, and the daily administration of thalidomide for 53 weeks was generally well tolerated. The $200 \mathrm{mg} / \mathrm{kg}$ dose was conservatively regarded as the no-observed-adverse effect level. Green-coloured urine, white particulate matter in the faeces, enlarged female mammary tissue with dilatation of ducts and hyperplasia of the glandular epithelium, prolonged duration of oestrus, osseous yellow discoloration and accumulation of bile pigment in the liver were attributed to different doses of thalidomide administration. 
Sedation in healthy dogs following up to $1000 \mathrm{mg} / \mathrm{kg}$ of thalidomide administration was not observed (Teo and others 2001). In contrast, somnolence was present in approximately 50 per cent of the patients submitted to HD, and less than 10 per cent presented with a significant impact in the quality of life and activities of daily living. The difference in sedation observations may be due to an increased perception of somnolence by client-owned dogs compared with study dogs, the subjective evaluation of pet owners in the present study and differences in studied populations: healthy and young beagles (Teo and others 2001) and older patients presenting with advanced clinical stage mammary gland neoplasms and other comorbidities.

The low incidence of discrete ultrasound alterations found in the present study were considered incidental and possibly unrelated to thalidomide administration. No thalidomide-related differences in the absolute and relative organ weights or microscopic changes were observed in healthy beagles (Teo and others 2001). Patients were staged again every three months, which may not be enough to precisely diagnose the moment of the disease progression in advanced clinical stage mammary gland neoplasms. Disease progression may not be associated to clinical signs and the chosen interval may be inadequate to evaluate the clinical benefit of the thalidomide treatment.

Blood work in most dogs with mammary gland tumours is normal, unless they have other concurrent medical problems or non-specific age-related changes (Sorenmo 2003). Most of the significant haematological and serum biochemistry changes following thalidomide administration described in healthy beagle dogs were small in magnitude, with no morphological and histopathological correlates, and all parameters returned to normal in the recovery dogs (Teo and others 2001). The significant CBC and SBP alterations of the present study were also considered small in magnitude, and were not related to treatment interruption or dose reduction. The majority of patients enrolled in the present study had been recently submitted to chemotherapy before thalidomide treatment was initiated. Therefore, the increases described in $\mathrm{CBC}$ following thalidomide administration may be partially due to a reversal of the myelosuppressive effects of chemotherapy. The bone marrow is sensitive to the toxic effects of chemotherapy, and neutropenia, thrombocytopenia, and, rarely, anaemia are described (Lana and Dobson 2011).

CBC analysis in mice treated with carboplatin followed by thalidomide demonstrated an increase in haematocrit, erythrocytes, haemoglobin, MCV, total leucocyte count, lymphocytes and platelets, and a decrease in eosinophils, neutrophils and monocytes, when compared with the control group. No alterations were found in the biochemical evaluation of AST, GGT, urea and creatine (De Souza and others 2014). Leucocytosis may be an important event in the anti-neoplastic immunomodulatory response of thalidomide and should be considered a relevant clinical parameter (Dos Reis and others 2014). Haematological improvement of the erythroid and, to a lesser extent, the megakaryocytic lineages, and rare neutrophil responses, were also described in acute myeloid leukaemia in human beings (Steins and others 2003). The limited CBC and SBP alterations described in $\mathrm{HD}$ and $\mathrm{LD}$ thalidomide were desirable, particularly for elderly patients with advanced neoplasms. The frequency of $\mathrm{CBC}$ and SBP monitoring every three months was considered adequate due to the limited alterations caused by thalidomide administration. However, specific patients may need more careful monitoring, especially in cases with pre-existing abnormalities or progressive disease.

A restricted programme under a Risk Evaluation and Mitigation Strategy (REMS) of the USA, the THALIDOMID REMS programme, recommends that if there is contact with non-intact thalidomide capsules or powder contents or if healthcare providers or other caregivers are exposed to bodily fluids from patients receiving thalidomide, the exposed area should be washed with soap and water. Appropriate precautions should be utilised, such as wearing gloves to prevent the potential cutaneous exposure to the drug (Celgene 2015). Teo and others (2001) periodically observed a white particulate residue in the faeces of beagles treated with thalidomide that appeared to be unabsorbed thalidomide, although chemical analysis was not performed. For safety reasons, the pet owners of the present study were requested to avoid cutaneous exposure to the drug by wearing disposable gloves and to avoid contact with bodily fluids of the animals. In the case of an accidental exposure, the recommendation was to wash the exposed area with soap and water.

Thalidomide administration was well tolerated in canine patients presenting with advanced clinical staging mammary gland neoplasms. Both studied doses did not impair the activities of daily living of most of the studied population; however, the proposed LD should be considered when excessive somnolence is found. Further studies are warranted to investigate the therapeutic benefit of thalidomide in canine mammary gland neoplasms and other neoplasms. The lack of a washout period between the HD and LD is a limitation of the present study and the toxicity evaluation of the LD individually were therefore hindered. Future thalidomide kinetic studies should be performed in dogs in order to better evaluate the absorption and metabolisation of the drug in several different moments in order to choose optimal doses and administration periods for specific diseases.

Funding This research was supported by the Fundação de Amparo à Pesquisa do Estado de São Paulo (FAPESP Grant 2014/01329-9) and the Conselho Nacional de Desenvolvimento Científico e Tecnológico (CNPq Grant 302449/2013-2).

\section{References}

BRODEY, R. S., GOLDSCHMIDT, M. H. \& ROSZEL, J. R. (1983) Canine mammary gland neoplasms. Journal of the American Animal Hospital Association 19, 61-90

CASSALI, G., LAVALle, G., FERREIRA, E., ESTRElA-LimA, A., NARDI, A., GHEVER, C., SOBRAL, R., AMORIM, R., OLIVEIRA, L., SUEIRO, F, BESERRA, H., BERTAGNOLLI, A., GAMBA, C., DAMASCENO, K., CAMPOS, C. ARAUJO, M., CAMPOS, L., MONTEIRO, L., NUNES, F., HORTA, R., REIS, D., LUVIZOTTO, M., MAGALHAES, G., RAPOSO, J., FERREIRA, A., TANAKA, N., GRANDI, F, UBUKATA, R., BATSCHINSKI, K., TERRA, E., SALVADOR, R., JARK, P., DELECRODI, J., NASCIMENTO, N., SILVA, D., SILVA, L., FERREIRA, K., FREHSE, M., SANTIS, G., SILVA, E., GUIM, T., KERR, B., CINTRA, P., SILVA F, LEITE, J., MELLO, M., FERREIRA, M., FUKUMASU, H., SALGADO, B. \& TORRES, R. (2014) Consensus for the diagnosis, prognosis and treatment of canine mammary tumors - 2013. Brazilian Journal of Veterinary Pathology 7, 38-69

CELGENE (2015) Thalidomid REMS. http://www.thalomidrems.com/. Accessed October 5, 2016

CHAMBERLAIN, P. P., LOPEZ-GIRONA, A., MILLER, K., CARMEL, G., PAGARIGAN, B., CHIE-LEON, B., RYCHAK, E., CORRAL, L. G., REN, Y. J., WANG, M., RILEY, M., DELKER, S. L., ITO, T., ANDO, H., MORI, T., HIRANO Y., HANDA, H., HAKOSHIMA, T., DANIEL, T. O. \& CATHERS, B. E. (2014) Structure of the human Cereblon-DDB1-lenalidomide complex reveals basis for responsiveness to thalidomide analogs. Nature Structural and Molecular Biology 21, 803-809

DE SOUZA, C. M. ARAÚJO E SILVA, A. C., DE JESUS FERRACIOLLI, C MOREIRA, G. V., CAMPOS, L. C., DOS REIS, D. C., LOPES, M. T., FERREIRA, M. A., ANDRADE, S. P. \& CASSALI, G. D. (2014) Combination therapy with car boplatin and thalidomide suppresses tumor growth and metastasis in 4T1 murine breast cancer model. Biomedicine and Pharmacotherapy 68, 51-57

DELFORGE, M., BLADE, J., DIMOPOULOS, M. A., FACON, T., KROPFF, M., LUDWIG, H., PALUMBO, A., VAN DAMME, P., SAN-MIGUEL, J. F. \& SONNEVELD, P. (2010) Treatment-related peripheral neuropathy in multiple myeloma: the challenge continues. The Lancet Oncology 11, 1086-1095

DIMOPOULOS, M. A. \& ELEUTHERAKIS-PAPAIAKOVOU, V. (2004) Adverse effects of thalidomide administration in patients with neoplastic diseases. American Journal of Medicine 117, 508-515

DOS REIS, D., SOUZA, C., CAMPOS, L., SILVA, A., LOPES, M., CASSALI, G., \& FERREIRA, E. (2014) Thalidomide promotes leukocytosis in mice inoculated with 4T1 mammary carcinoma. Journal Brasileiro de Patologia e Medicina Laboratorial 50, 64-66

ESCUDIER, B., LASSAU, N., COUANET, D., ANGEVIN, E., MESRATI, F., LEBORGNE, S., GAROFANO, A., LEBOULAIRE, C., DUPOUY, N., LAPLANCHE, A. (2002) Phase II trial of thalidomide in renal-cell carcinoma. Annals of Oncology 13, 1029-1035

FLORENCE, A. L. (1960) Is Thalidomide to Blame? British Medical Journal 2, 1954. ITO, T., ANDO, H., SUZUKI, T., OGURA, T., HOTTA, K., IMAMURA, Y., YAMAGUCHI, Y. \& HANDA, H. (2010) Identification of a primary target of thalidomide teratogenicity. Science 327, 1345-1350

JANKOWSKI, M., FULTON, L., SHEAFOR, S., PRESCOTT, D. \& KHANNA, C. (1999) Ongoing evaluation of single agent thalidomide in dogs with measurable cancer. In Veterinary Cancer Society 19th Annual Meeting

KARAYANNOPOULOU, M., KALDRYMIDOU, E., CONSTANTINIDIS, T. C. \& DESSIRIS, A. (2001) Adjuvant Post-operative Chemotherapy in Bitches with Mammary Cancer. Journal of Veterinary Medicine Series A 48, 85-96 
LANA, S. E. \& DOBSON, J. M. (2011) Principles of chemotherapy. In BSAVA Manual of canine and feline oncology. 3rd edn. Eds J. M. DOBSON \& B. D. X. LASCELLES.. British Small Animal Veterinary Association. pp 67-79

LAVALLE, G. E., DE CAMPOS, C. B., BERTAGNOLLI, A. C. \& CASSALI, G. D. (2012) Canine malignant mammary gland neoplasms with advanced clinical staging treated with carboplatin and cyclooxygenase inhibitors. In Vivo 26, 375-379

LENZ, W. (1988) A short history of thalidomide embryopathy. Teratology 38, 203-215.

MARIA DE SOUZA, C., FONSECA DE CARVALHO, L., DA SILVA VIEIRA, T, CÂNDIDA ARAÚJO E SILVA, A., TERESA PAZ LOPES, M., ALVES NEVES DINIZ FERREIRA, M., PASSOS ANDRADE, S. \& DANTAS CASSALI, G. (2012) Thalidomide attenuates mammary cancer associated-inflammation, angiogenesis and tumor growth in mice. Biomedicine and Pharmacotherapy 66, 491-498

MARCONATO, L., BUCHHOLZ, J., KELLER, M., BETTINI, G., VALENTI, P. \& KASER-HOTZ, B. (2013) Multimodal therapeutic approach and interdisciplinary challenge for the treatment of unresectable head and neck squamous cell carcinoma in six cats: A pilot study. Veterinary and Comparative Oncology 11, 101-112

MCBRIDE, W. G. (1961) Thalidomide and congenital abnormalities. Public Health 278, 1358

MCBRIDE, W. G. (1977) Thalidomide embryopathy. Teratology 16, 79-82

NOVOSAD, C. A. (2003) Principles of treatment for mammary gland tumors Clinical Techniques in Small Animal Practice 18, 107-109

OWEN, L. N. (1980) TNM Classification of Tumors in Domestic Animals. 1st edn. World Health Organization

SINGHAL, S. \& MEHTA, J. (2002) Thalidomide in cancer. Biomedicine and Pharmacotherapy 56, 4-12

SORENMO, K. U. (2003) Canine mammary gland tumors. The Veterinary Clinics of North America. Small Animal Practice 33, 573-596

SORENMO, K. U., WORLEY, D. R. \& GOLDSCHMIDT, M. H. (2013) Tumors

of the mammary gland. In Withrow \& MacEwen's Small Animal Clinical Oncology. 5th edn. Eds S. J. WITHROW \& D. M. VAIL. W. B. Saunders Company. pp $538-556$

STEINS, M. B., BIEKER, R., PADRÓ, T., KESSLER, T., KIENAST, J., BERDEL, W. E \& MESTERS, R. M. (2003) Thalidomide for the treatment of acute myeloid leukemia. Leukemia \& Lymphoma 44, 1489-1493

STEWART, A. K. (2014) How thalidomide works against cancer. Science 343, 256-7 TEO, S., EVANS, M., EHRHART, J., BROCKMAN, M., ALLEN, D., MORGAN, M. STIRLING, D. \& THOMAS, S. (2000) Lack of peripheral neuropathy in Beagle dogs after 53 weeks oral administration of thalidomide capsules. Human and Experimental Toxicology 19, 615-622

TEO, S. K., COLBURN, W. A., TRACEWELL, W. G., KOOK, K. A., STIRLING D. I., JAWORSKY, M. S., SCHEFFLER, M. A., THOMAS, S. D. \& LASKIN, O. L. (2004) Clinical pharmacokinetics of thalidomide. Clinical Pharmacokinetics 43 311-327

TEO, S. K., EVANS, M. G., BROCKMAN, M. J., EHRHART, J., MORGAN, J. M., STIRLING, D. I. \& THOMAS, S. D. (2001) Safety profile of thalidomide after 53 weeks of oral administration in Beagle dogs. Toxicological Sciences 59 160-168

VETERINARY CO-OPERATIVE ONCOLOGY GROUP (2004) Veterinary cooperative oncology group - common terminology criteria for adverse events (VCOG-CTCAE) following chemotherapy or biological antineoplastic therapy in dogs and cats v1.1. Veterinary and Comparative Oncology 2, 194-213

WOODS, J. P., MATHEWS, K. A. \& BINNINGTON, A. G. (2004) Thalidomide for the treatment of hemangiosarcoma in dogs. Veterinary and Comparative Oncology 2, 108-109
要

CrossMark 